\title{
Current status of biosimilars in the treatment of inflammatory bowel diseases
}

\author{
Dong Il Park \\ Department of Internal Medicine, Kangbuk Samsung Hospital, Sungkyunkwan University School of Medicine, Seoul, Korea
}

Introduction of biological therapies have led to dramatic changes in the management of debilitating immune-mediated inflammatory bowel diseases (IBD) including ulcerative colitis and Crohn's disease. However, the long term use of these agents may be very expensive, placing a significant burden on National Healthcare Systems. The development of first biosimilar to infliximab, CT-P13 (Remsima; Celltrion Inc., Incheon, Korea and Inflextra; Hospiral, Lake Forest, Illinois, USA) has become another way to decrease the medical care cost and increase patient treatment option, but, actual equivalence of efficacy and safety of CT-P13 was investigated in rheumatic diseases only. The extrapolation of outcome from rheumatic trials to IBD and the interchangeability of CT-P13 with infliximab have come to be a matter of concern. Two recent retrospective studies reported the similarity of CT-P13 in terms of efficacy and safety. Infliximab biosimilars may be promising new treatment options for IBD patients, however, well-designed, prospective randomized non-inferiority trials should be needed to confidently integrate infliximab biosimilars into IBD treatment. (Intest Res 2016;14:15-20)

Key Words: Inflammatory bowel diseases; Biosimilar; Pharmacy; CT-P13

\section{INTRODUCTION}

Introduction of biological therapies in form of monoclonal antibodies or soluble cytokine receptors have led to dramatic improvements in the management of several debilitating immune-mediated inflammatory diseases including rheumatoid arthritis (RA), ankylosing spondylitis (AS), psoriasis, psoriatic arthritis, CD and UC. ${ }^{1-3}$ Especially, the use of tumor necrosis factor alpha (TNF- $\alpha$ ) antagonists, such as adalimumab, certolizumab, etanercept, golimumab, and infliximab especially applied early in the disease course have been shown to induce clinical remission and ward off structural damage by modifying disease progression, thus, resulting in reduced the need for corticosteroid treatment, hospitaliza-

\footnotetext{
Received October 23, 2015. Revised November 11, 2015. Accepted November 12, 2015.

Correspondence to Dong II Park, Department of Internal Medicine, Kangbuk Samsung Hospital, Sungkyunkwan University School of Medicine, 29

Saemunan-ro, Jongno-gu, Seoul 03181, Korea. Tel: +82-2-2001-8555,

Fax: +82-2-2001-2610,E-mail: diksmc.park@samsung.com

Financial support: None. Conflict of interest: None.
}

tion and surgery and improved quality of life of many patients. ${ }^{4}$ The incidence of some chronic IBD such as CD and UC is rising, which may increase the number of patients who are appropriate candidates for biological therapies.,

The biological agents are large and very complicated molecules, approximately 1,000 times larger than chemical drugs, which are produced by living cell cultures, thus requiring huge investment. The long duration of development and high production costs are cited as the main contributors to the high price of biological agents, therefore, prolonged use of these agents may be very expensive, placing a serious burden on National Healthcare Systems. ${ }^{7}$ As the patents for several TNF- $\alpha$ antagonists used in inflammatory diseases have or will soon expire in many countries around the world, the development of biosimilars has become another way to improve patient's outcomes and potentially lower healthcare costs. In this review, I aim to explore some of the most important aspects of the biosimilars focusing on their role in IBD.

\footnotetext{
๑ Copyright 2016. Korean Association for the Study of Intestinal Diseases. All rights reserved.

This is an Open Access article distributed under the terms of the Creative Commons Attribution Non-Commercial License (http://creativecommons.org/licenses/by-nc/4.0)

which permits unrestricted non-commercial use, distribution, and reproduction in any medium, provided the original work is properly cited.
} 


\section{WHAT IS BIOSIMILAR?}

A biosimilar is a protein-based medical product developed using recombinant DNA technology that has a molecular structure and biological properties highly similar to the innovator product that has been approved by drug related authorities, such as the European Medicines Agency (EMA) and the United States Food and Drug Administration (FDA). The FDA definition of a biosimilar makes this clear; a biosimilar is a biological product that is highly similar to the reference product not withstanding minor differences in clinically inactive components and that there are no clinically meaningful differences between the biological product and the innovator product in terms of the safety, purity, and potency. ${ }^{8}$ The manufacturing of biosimilar is more complex than the production of generic chemical drugs. It requires several steps, including the determination and growth of a vector, the host cell expression system, the cell expansion procedure, the protein recovery mechanism, the purification process and the formulation of the therapeutic protein into a drug. ${ }^{9}$ Even after patent expiration, manufacturing processes do not have to be disclosed, so there are likely to be appreciable differences in the manufacturing processes of biosimilars and their innovator product. Biosimilars are not generic products, so it is therefore likely that these differences in the manufacturing process will lead to subtle differences between them.

Drug related authorities such as EMA, FDA, and Health Canada hold their own guidance on requirements for demonstration of the similar nature of two biological products in terms of safety and efficacy. The EMA developed a specific legal pathway for sanction of biosimilar, in which it is recognized that biosimilar may not be identical, but must be similar to the original EU-approved innovator products in terms of efficacy, safety, and quality. ${ }^{10}$ The Biologics Price Competition and Innovation Act $^{11}$ designates an abbreviated licensing pathway for biosimilar in the USA, but the most stringent criteria for the approval of biosimilar are those of Health Canada. To date, a total of 20 biosimilars have been evaluated and 15 authorized in the EU. Based on the EMA and the World Health Organization (WHO) guidelines, several countries including Australia, Canada, China, India, Japan, Korea, and others have established or are establishing their own regulatory pathways for biosimilar development.

Biological agents, including adalimumab and infliximab, are seven of the 10 top grossing drugs in the world. ${ }^{8}$ For instance, the sales of infliximab in 2013 were 4 billion USD in USA and 2.2 billion USD in EU. ${ }^{12}$ The cost savings by using biosimilars are anticipated to be $25 \%-70 \%$ compared to their innovator product and this can make it easier to use biological agents for patients in need. Another possible benefit is the development of biobetter molecules which target the same validated epitope as the innovator product, but have been genetically modified to improve their pharmacokinetic properties, for example, optimization of glycosylation profiles to enhance effector functions or exchanging of $\mathrm{Fc}$ domains to increase serum half-life or antibody-dependent cellular cytotoxicity. ${ }^{13}$

\section{WHAT ARE THE REGULATORY REQUIREMENTS?}

It is common for registered biological agents to undergo manufacturing process improvements and changes during the life cycle of the drug after approval. Even minor adjustments in manufacturing processes can change biological functions, efficacy or safety profile of the same biological agent. When such a change takes place, the manufacturer should carry out a comparability exercise to prove that the change does not adversely affect the identity, purity, or potency of the agent. For example, during the manufacturing process of recombinant erythropoietin product, a replacement of human serum albumin as a stabilizer with the synthetic detergent polypsorbate 80 and glycine, resulted in an immune response against membrane-bound erythroblasts in the bone marrow. This minor change in the manufacturing process induced the formation of autoantibodies to both endogenous and exogenous erythropoietin, increasing the incidence of pure red cell aplasia, a rare but fatal disease. ${ }^{14}$ Neutralizing antibodies to erythropoietin were also produced by the biosimilar HX575 because of tungsten contamination during the making of the syringes which caused protein denaturation and aggregation of HX batches. ${ }^{15}$ Virtually all monoclonal antibodies are immunogenic and can induce antidrug antibody formation. The development of antidrug antibody may lead to accelerated drug clearance, reduced drug efficacy and higher risk of infusion reactions. Therefore, immunogenicity of monoclonal antibodies is a major safety concern for the biosimilars not only by many clinicians but also the regulatory authorities.

The principles conducting the comparability exercise required for biosimilar development are similar to those for innovator product changed manufacturing process, however, are more extensive and require at least one clinical study. Therefore, the key question for biosimilars is not whether differences exist compared with the innovator product, whether such differences are clinically significant. The EMA and FDA announced specific requirements for the com- 
parability exercise of biosimlar development (Table 1), ${ }^{8,10,16}$ For example, both the EMA and the FDA require that the primary amino acid sequence, potency, dose, and route of administration of the biosimilar must be the same as the innovator product. Higher-order structures, post-translational modifications and other potential variants have to be as similar as possible to the innovator product, with adequate analyses to prove that any difference do not make an influence on clinical efficacy, safety, or immunogenicity. Both the EMA and the FDA require one or more adequately powered equivalence trials to demonstrate similar efficacy, safety and immunogenicity for the biosimilar and innovator product.

\section{EXTRAPOLATION ISSUES}

The biosimilar to infliximab, CT-P13 has been approved recently in several countries based on a single equivalence trial conducted in patients with RA, ${ }^{17}$ supplemented by a pharmacokinetic study on AS. ${ }^{18}$ In addition to approving the CT-P13 for RA and AS, the EMA and Korean FDA allowed full label extrapolation including CD, UC, psoriasis and psoriatic arthritis although this agent was not tested in these indicated patients, other regulatory agencies allowed partial extrapolation. ${ }^{15}$ Health Canada approved the CT-P13 for all indications except CD and UC based on the differences including Fc $\gamma$ RIIIa receptor binding, the level of afucosylation and some antibody-dependent cell-medicated cytotoxicity (ADCC) issue. ${ }^{19}$ However, the initial differences detected on ADCC were only seen in vitro using target cells that were engineered to overexpress membrane TNF and using enriched natural killer cells from CD patients with the high affinity genotypes of the FcR. When ADCC activity was tested using more physiologic effector cells such as whole blood or isolated peripheral blood mononuclear cells, the difference in fucosylation for CT-P13 and the innovator drug did not impact ADCC, ${ }^{20}$ questioning the clinical significance of the observed differences in Fc $\gamma$ RIIa binding. Another important consideration for bioequivalence testing is to select a patient population and clinical end point most sensitive to detect clinically significant differences in efficacy and safety. If the difference in efficacy between a test drug and placebo is small, it is difficult to prove a difference between them even if there is. If a biologic agent is shown to be biosimilar in the highest placebo-adjusted efficacy model (such as those of the highest response rate and lowest placebo effect), it may be approved for use across all indications. Of the six indications of infliximab, the greatest placebo-adjusted response was found in plaque psoriasis, followed by psoriatic arthritis and CD. In contrast, RA revealed the smallest placebo-adjusted response, in other words, RA is likely to be a less sensitive clinical model to demonstrate a potential difference in efficacy between CT-P13 and infliximab. ${ }^{21}$ The development

Table 1. Rigorous Regulatory Standards for Biosimilars: The FDA and the EMA Clinical Characteristics and Clinical Study Requirements

\begin{tabular}{|c|c|c|}
\hline Characteristics & \multicolumn{2}{|c|}{ FDA and EMA } \\
\hline Potency & \multicolumn{2}{|l|}{ Must match the reference product } \\
\hline Route of administration & \multicolumn{2}{|l|}{ Must be the same as the reference product } \\
\hline $\begin{array}{l}\text { Higher-order structures, post-translational } \\
\text { modifications and other potential variants }\end{array}$ & \multicolumn{2}{|c|}{$\begin{array}{l}\text { Must be as similar as possible to the reference product, with adequate analyses to demonstrate } \\
\text { that any differences do not impact on clinical efficacy, safety, immunogenecity }\end{array}$} \\
\hline Pharmacokinetic studies & Comparative human studies & Single-dose, comparative human studies \\
\hline Pharmacodynamic studies & $\begin{array}{l}\text { Comparative human studies, where } \\
\text { clinically relevant measures are available }\end{array}$ & $\begin{array}{l}\text { Combined with PK studies where a clinically relevant PD } \\
\text { end point is available; otherwise nonclinical evaluation } \\
\text { required }\end{array}$ \\
\hline Efficacy & $\begin{array}{l}\text { At least one, adequately powered } \\
\text { equivalence trial }\end{array}$ & $\begin{array}{l}\text { Highly sensitive, dose-comparative PD studies may be } \\
\text { sufficient. Otherwise, at least one, adequately powered } \\
\text { equivalence trial }\end{array}$ \\
\hline Immunogenecity & $\begin{array}{l}\text { At least two comparative trials, one } \\
\text { pre- and one post-marketing }\end{array}$ & Must be assessed during the safety trial \\
\hline
\end{tabular}

FDA, Food and Drug Administration; EMA, European Medicines Agency; PK, pharmacokinetic; PD, pharmacodynamics.

Adapted with permission from Dörner T et al. BMJ Publishing Group Ltd. ${ }^{16}$ 
of antidrug antibodies or Immunogenicity is the primary safety concern for biological agents, therefore, the regulatory agencies require that the immunogenicity profile of biosimilars be sufficiently characterized. The immunogenicity profile should be studied in the patient population with the highest risk of an immune responses. ${ }^{8}$ The highest incidence of immunogenicity was detected in $\mathrm{CD}^{22}$ up to $61 \%$, whereas, it was lowest in RA, less than $10 \%{ }^{23}$ which was even further suppressed by the concomitant use of immunosuppressant. ${ }^{24}$

Extrapolation into other indications is essential to keep the cost of biosimilars competitive. The decision to extrapolate should be based primarily on the demonstration of similarity through extensive comparability studies that compare the physicochemical attributes and the biological activity between the biosimilar and innovator product provided by the regulatory guidelines. If all indications have to be studied, time-consuming prior authorization would minimize the cost reducing effect of biosimilar. The EMA, the FDA and the Korean FDA provide the regulatory guidelines regarding extrapolation of clinical data for biosimilar (Table 2). ${ }^{21}$

\section{INTERCHANGEABILITY AND AUTOMATIC SUBSTITUTION}

Interchangeability between the innovator product and its biosimilar remains an important subject for discussion. As defined by the FDA, interchangeability indicates that bio- similar may be expected to demonstrate the same clinical result as the innovator product in any given patient and if biosimilar is administered more than once to an individual, the risk in terms of safety or diminished efficacy of alternating or switching between the use of biosimilar and the innovator product is not greater than the risk of using the innovator product without such alteration or switch. ${ }^{7}$ Thus, interchangeability represents a higher standard than demonstrating biosimilarity to the innovator product. At the present time, the FDA has not yet provided guidance on the method of studying needed to enable a determination of interchangeability.

The American Academy of Dermatology has guided its recommendations for the process of substitution of a biosimilar for a innovator biologic (Table 3). ${ }^{24}$ Most clinicians argue against the interchangeability of biosimilars.

In a head-to-head comparison cross-over study, switching from epoetin- $\alpha$ to the epoetin biosimilar SB309 resulted in, approximately, a $10 \%-15 \%$ increase in the dose required and transiently decreased the hemoglobin concentration by $5 \%{ }^{25}$ Switching back from SB309 to epoetin- $\alpha$ reduced the dose required by almost $10 \%$ and increased hemoglobin levels by $10 \%$. The proponents of interchangeability argue that changes, to date, in the manufacturing process did not preclude full interchangeability. ${ }^{26}$ Indeed, most clinicians were not aware of these changes in manufacturing. The EMA has recently designated a biosimilar as automatically substitutable, although each country will follow its own national guidelines.

Table 2. Summary of Regulartory Guidelines Regarding Extrapolation of Clinical Data for Biosimilars

\begin{tabular}{|c|c|c|c|}
\hline Concern & FDA & EMA & KFDA/WHO \\
\hline $\begin{array}{l}\text { Mechanism of action may be } \\
\text { distinct in each therapeutic } \\
\text { indication }\end{array}$ & \multicolumn{2}{|c|}{$\begin{array}{l}\text { Extrapolation will be considered on a case-by-case basis. Where } \\
\text { the mechanism of action differs between indications or are not fully } \\
\text { understood, separate clinical trials are likely to be necessary }\end{array}$} & $\begin{array}{l}\text { The clinically relevant mechanisms of action } \\
\text { and/or the involved receptors should be the } \\
\text { same for the different indications }\end{array}$ \\
\hline $\begin{array}{l}\text { For a given mechanism of action, } \\
\text { several mechanisms may exist }\end{array}$ & \multicolumn{2}{|c|}{$\begin{array}{l}\text { Almost superimposable biological data must be provided, covering } \\
\text { all functional aspects of the agent, even if not considered clinically } \\
\text { relevant. Where mechanisms of action are not fully understood, } \\
\text { separate clinical trials are likely to be necessary }\end{array}$} & See above \\
\hline $\begin{array}{l}\text { Risk of undertreating patients/varied } \\
\text { safety profiles in different patient } \\
\text { groups }\end{array}$ & \multicolumn{2}{|c|}{$\begin{array}{l}\text { Data should be produced using a patient population and clinical } \\
\text { end point most sensitive to detect clinically meaningful } \\
\text { differences in efficacy and safety }\end{array}$} & $\begin{array}{l}\text { A sensitive clinical test model should be used } \\
\text { that is able to detect potential differences } \\
\text { between the follow-on and reference } \\
\text { products. } \\
\text { The safety and immunogenicity profiles of the } \\
\text { follow-on products should be sufficiently } \\
\text { characterized. }\end{array}$ \\
\hline $\begin{array}{l}\text { Individual patient characteristics } \\
\text { may influence the response }\end{array}$ & $\begin{array}{l}\text { Careful consideration must be given } \\
\text { to comorbidities/concomitant } \\
\text { medications and intersubject } \\
\text { variability }\end{array}$ & $\begin{array}{l}\text { Homogenous population should } \\
\text { be used- differences in response } \\
\text { can then be attributed to the } \\
\text { biosimilar }\end{array}$ & \\
\hline
\end{tabular}

FDA, Food and Drug Administration; EMA, European Medicines Agency; KFDA, Korean Food and Drug Administration; WHO, World Health Organization. Adapted with permission from Lee H. Springer Science+Business Media. ${ }^{21}$ 
Table 3. Summary of the Position Statement on Generic Therapeutic and Biosimilar Substitution

The biosimilar must have a unique nonproprietary name and be designated as interchangeable by the FDA.

The prescribing physician provides permission for the substitution to the pharmacist.

The patient is informed and educated about the switch.

The pharmacist informs the prescriber at the time of dispensing.

A permanent record is made of the switch in the patient's medical record.

FDA, Food and Drug Administration.

\section{CLINICAL STUDIES IN IBD}

Currently, there are no prospective randomized noninferiority trials evaluating the clinical efficacy and safety, as well as interchangeability of a biosimilar in IBD patients. We performed a retrospective multicenter study evaluating the clinical efficacy and safety of CT-P13 in 32 anti-TNF naïve CD patients and 42 anti-TNF naïve UC patients. ${ }^{27}$ In antiTNF naïve CD patients, clinical response rates at week 8,30 and 54 were $90.6 \%, 95.5 \%$ and $87.5 \%$, respectively, and clinical remission rates at week 8,30 and 54 were $84.4 \%, 77.3 \%$ and $75.0 \%$, respectively. In anti-TNF naïve UC patients, clinical response rates at week 8,30 and 54 were $81.0 \%$, $91.3 \%$ and $100 \%$, respectively, and clinical remission rates at week 8,30 and 54 were $38.1 \%, 47.8 \%$ and $50.0 \%$, respectively, while mucosal healing rates at week 8,30 and 54 were $58.3 \%, 66.7 \%$, and $66.7 \%$, respectively. We also evaluated the interchangeability of CT-P13 in 27 CD patients and 9 UC patients after switching from its originator. The efficacy of CTP13 was maintained in 92.6\% (25/27) of CD patients and in $66.7 \%$ (6/9) of UC patients for at least 32 weeks after switching from its originator. There was no infusion reaction or any serious adverse events related to CT-P13 in these patients.

Another post-marketing study ${ }^{28}$ included patients with active moderate-to-severe $\mathrm{CD}$, fistulizing $\mathrm{CD}$, or moderate-tosevere UC treated with CT-P13 and followed for 30 weeks. Clinical response rates at week 14 and 30 in patients with moderate-to-severe CD were $87.2 \%(34 / 39)$ and $79.5 \%$ (31/39), while clinical remission rates at the same time points were $69.2 \%$ (27/39) and 59.0\% (23/39), respectively. In the case of fistulizing $\mathrm{CD}$, the clinical response and remission rates were $66.7 \%(4 / 6)$ and $33.3 \%(2 / 6)$ at week 14 and $66.7 \%(4 / 6)$ and $50 \%(3 / 6)$ at week 30 , respectively. For patients with moderate-to-severe UC, clinical response and remission rates were $75.5 \%(40 / 53)$ and $49.1 \%(26 / 53)$ at week 14 and $72.2 \%(39 / 54)$ and $37.0 \%(20 / 54)$ at week 30 , respectively. Treatment-related adverse events occurred in $10 \%$ of patients and were mostly mild-moderate in severity. There were five serious treatment-related adverse events (two infusion-related reactions, two infections, one abdominal pain) and no cases of malignancy, pneumonia, or death.

A recent study ${ }^{29}$ using 125 IBD patients' and controls' sera demonstrated that anti-Remicade antibodies in IBD patients recognize and functionally inhibit Remsima to a similar degree, suggesting similar immunogenicity profile. All 69 positive anti-Remicade sera were cross-reactive with Remsima. Antibody to infliximab titers against Remicade or Remsima were strongly correlated ( $\mathrm{r}$-values between 0.92 and 0.99 , $P<0.001)$. Anti-Remicade antibodies of IBD patients exerted similar functional inhibition on Remsima or Remicade TNF- $\alpha$ binding capacity.

\section{CONCLUSIONS}

Clinicians should be aware of the benefits and concerns regarding the clinical application of biosimilar in IBD patients. Biosimilars represent an opportunity to reduce healthcare costs even taking into account similarity in terms of efficacy and safety compared with their original products. However, well-designed, prospective randomized non-inferiority trials for efficacy and safety, as well as immunogenicity and interchangeability should be needed to confidently integrate biosimilars into IBD treatment.

\section{REFERENCES}

1. Wiens A, Venson R, Correr CJ, Otuki MF, Pontarolo R. Metaanalysis of the efficacy and safety of adalimumab, etanercept, and infliximab for the treatment of rheumatoid arthritis. Pharmacotherapy 2010;30:339-353.

2. Bansback N, Sizto S, Sun H, Feldman S, Willian MK, Anis A. Efficacy of systemic treatments for moderate to severe plaque psoriasis: systematic review and meta-analysis. Dermatology 2009;219:209-218.

3. Billiet T, Rutgeerts P, Ferrante M, Van Assche G, Vermeire S. Targeting TNF- $\alpha$ for the treatment of inflammatory bowel disease. Expert Opin Biol Ther 2014;14:75-101.

4. Schnitzler F, Fidder H, Ferrante M, et al. Long-term outcome of treatment with infliximab in 614 patients with Crohn's disease: results from a single-centre cohort. Gut 2009;58:492-500.

5. Molodecky NA, Soon IS, Rabi DM, et al. Increasing incidence and prevalence of the inflammatory bowel diseases with time, based on systematic review. Gastroenterology 2012;142:46-54. 
6. Hu PJ. Inflammatory bowel disease in Asia: the challenges and opportunities. Intest Res 2015;13:188-190.

7. Liu Y, Wu EQ, Bensimon AG, et al. Cost per responder associated with biologic therapies for Crohn's disease, psoriasis, and rheumatoid arthritis. Adv Ther 2012;29:620-634.

8. US Food and Drug Administration. Guidance for industry: quality considerations in demonstrating biosimilarity to a reference protein product. http://www.fda.gov/downloads/Drugs/ GuidanceComplianceRegulatoryInformation/Guidances/ UCM291134.pdf. Published 2012. Accessed May 21, 2014.

9. Gecse KB, Khanna R, van den Brink GR, et al. Biosimilars in IBD: hope or expectation? Gut 2013;62:803-807.

10. European Medicines Agency. Procedural advice for users of the centralized procedure for similar biological medicinal products applications. London, UK: European Medicines Agency; 2011. EMA/940451/2011.

11. US Government. Title VII - Improving access to innovative medical therapies: Subtitle A - Biologics price competition and innovation. In: H.R. 3590 - Patient protection and affordable care act. 111th Cong;2009-2010:686-703. http://www.fda.gov/ downloads/Drugs/GuidanceComplianceRegulatoryInformation/UCM216146.pdf. Accessed November 20, 2013.

12. Merck. 2013 Merck Annual Report. http://www.merck.com/ investors/financials/annual-reports/. Accessed March 5, 2014.

13. Beck A, Sanglier-Cianférani S, Van Dorsselaer A. Biosimilar, biobetter, and next generation antibody characterization by mass spectrometry. Anal Chem 2012;84:4637-4646.

14. Schellekens H. Immunologic mechanisms of EPO-associated pure red cell aplasia. Best Pract Res Clin Haematol 2005;18:473-480.

15. Jelkmann W. Biosimilar epoetins and other "follow-on" biologics: update on the European experiences. Am J Hematol 2010;85:771-780.

16. Dörner T, Strand V, Castañeda-Hernández G, et al. The role of biosimilars in the treatment of rheumatic diseases. Ann Rheum Dis 2013;72:322-328.

17. Yoo DH, Hrycaj P, Miranda P, et al. A randomised, double-blind, parallel-group study to demonstrate equivalence in efficacy and safety of CT-P13 compared with innovator infliximab when coadministered with methotrexate in patients with active rheumatoid arthritis: the PLANETRA study. Ann Rheum Dis 2013;72:1613-1620.

18. Park W, Hrycaj P, Jeka S, et al. A randomised, double-blind, multicentre, parallel-group, prospective study comparing the pharmacokinetics, safety, and efficacy of CT-P13 and innovator infliximab in patients with ankylosing spondylitis: the PLANETAS study. Ann Rheum Dis 2013;72:1605-1612.
19. Summary basis of decision (SBD) for Remsima. Health Canada Web site. http://www.hc-sc.gc.ca/dhp-mps/prodpharma/sbdsmd/drug-med/sbd_smd_2014_remsima_160195-eng.php. Published April 1, 2014. Accessed April 9, 2014.

20. European Medicines Agency; Committee for Medicinal Products for Human Use (CHMP). Assessment report: inflectra. http://www.ema.europa.eu/docs/en_GB/document_ library/EPAR_-_Public_assessment_report/human/002778/ WC500151490.pdf. Published June 27, 2013. Accessed December 2,2014 .

21. Lee H. Is extrapolation of the safety and efficacy data in one indication to another appropriate for biosimilars? AAPS J 2014;16:22-26.

22. Baert F, Noman M, Vermeire S, et al. Influence of immunogenicity on the long-term efficacy of infliximab in Crohn's disease. N Engl J Med 2003;348:601-608.

23. Flood J. Tumor necrosis factor inhibitors in the treatment of chronic inflammatory diseases. A review of immunogenicity and potential implications. Manag Care 2009;18(4 Suppl 3):1-5.

24. American Academy of Dermatology and AAD Association. Position statement on generic therapeutic \& biosimilar substitution. http://www.aad.org/Forms/Policies/Uploads/PS/PSGeneric\%20Therapeutic\%20and\%20\%20Biosimilar\%20Substitution.pdf. Published March 29, 2013. Last amended August 3, 2013. Accessed May 9, 2014.

25. Wizemann V, Rutkowski B, Baldamus C, Scigalla P, Koytchev R; Epoetin Zeta Study Group. Comparison of the therapeutic effects of epoetin zeta to epoetin alfa in the maintenance phase of renal anaemia treatment. Curr Med Res Opin 2008;24:625-637.

26. McCamish M, Woollett G. The continuum of comparability extends to biosimilarity: how much is enough and what clinical data are necessary? Clin Pharmacol Ther 2013;93:315-317.

27. Jung YS, Park DI, Kim YH, et al. Efficacy and safety of CT-P13, a biosimilar of infliximab, in patients with inflammatory bowel disease: a retrospective multicenter study. J Gastroenterol Hepatol 2015;30:1705-1712.

28. Park SH, Kim YH, Lee JH, et al. Post-marketing study of biosimilar infliximab (CT-P13) to evaluate its safety and efficacy in Korea. Expert Rev Gastroenterol Hepatol 2015;9(Suppl 1):35-44.

29. Ben-Horin S, Yavzori M, Benhar I, et al. Cross-immunogenicity: antibodies to infliximab in Remicade-treated patients with IBD similarly recognise the biosimilar Remsima [published online ahead of print April 20, 2015]. Gut. doi:10.1136/ gutjnl-2015-309290. 